\title{
IMPACTOS DA IMPLANTAÇÃO DA BARRAGEM NO RIBEIRÃO JOÃO LEITE SOBRE A OFERTA DE HORTIFRUTI NA GRANDE GOIÂNIA
}

\author{
IMPACTS OF THE IMPLANTATION OF THE RIBEIRÃO JOÃO LEITE BARRAGE \\ ON THE SUPPLY OFFER OF FRUIT AND VEGETABLES IN GOIÂNIA
}

\author{
LES IMPACT DE IMPLANTATION DE LA BARRAGE DU RIBEIRÃO JOÃO LEITE \\ SUR LES OFFRE DE ÉPICERIE DANS GOIÂNIA
}

\author{
Silvio Braz de Sousa - Universidade Federal de Goiás - Goiânia - Goiás - Brasil \\ sousasb@gmail.com
}

\section{Resumo}

A bacia hidrográfica do Ribeirão João Leite (BHRJL) foi transformada em Área de Proteção Ambiental (APA) quando se iniciou a implantação de um reservatório de água potável em seu leito, para abastecimento da Grande Goiânia, no ano de 2002. Este artigo discute o impacto das restrições ambientais da nova APA na produção de hortifruti, que em 2010 representou $35 \%$ dos produtos oferecidos na Central de Abastecimento de Goiás (CEASA-GO). Foram utilizados dados estatísticos da CEASA, IBGE e imagens do satélite Thailand Earth Observation (THEOS) para a construção de gráficos, mapas temáticos e de um mapa de uso e cobertura da terra (2011). Observou-se que $27 \%$ da área cultivada nos sete municípios da BHRJL são abrangidos pela APA, onde a produção de hortifruti é predominante, e que as restrições à produção agropecuária da BHRJL tendem a provocar mudanças técnicas e econômicas que irão influenciar na quantidade, qualidade e preço dos produtos ofertados pelas propriedades rurais da APA à Grande Goiânia.

Palavras-chave: Ribeirão João Leite, Área de Proteção Ambiental, produção de hortifruti, Grande Goiânia.

\section{Abstract}

The Ribeirão João Leite watershed (BHRJL) was transformed into an Area of Environmental Protection (APA) due to the implementation of a water reservoir in its riverbed for the provision of the Great Goiannia in the year 2002. This paper discusses the impact of the environmental restriction of the new APA in the production of fruits and vegetables, which in 2010 represented $35 \%$ of the products offered by the Central Supply of Goiás (CEASAGO). Statistic data from CEASA, IBGE and satellite images from the satellite Thailand Earth Observation (THEOS) were used for the construction of graphs, thematic maps, and a map of land cover and land use (2011). It was observed that $27 \%$ of the cultivated areas in the seven municipalities of the BHRJ are covered by the APA, where the production of fruits and vegetables are predominant, and that the restrictions to the agricultural production of the BHRJL will bring technical and economic changes, which will influence in the quantity, quality and price of the products offered by the rural properties of the APA to the Great Goiânia.

Keywords: Ribeirão João Leite, Area of Environmental Protection, production of fruits and vegetables, Great Goiânia.

\section{Resumè}

Le bassin hydrologique du Ribeirão João Leite a été transformé en zone de protection de l'environnement (APA) quand il a commencé la construction d'un réservoir d'eau potable dans votre lit pour alimenter le Grand Goiânia, en 2002. Cet article traite de l'impact des contraintes environnementales dans la nouvelles APA sur la production de produits d'épicerie, qui en 2010 représentait $35 \%$ des produits offerts dans les Goiás alimentation centrale (GO-CEASA). Nous avons utilisé les données statistiques du CEASA, IBGE et I'imagerie par satellite Thailand Earth Observation (THEOS) pour la construction des graphiques, des cartes thématiques et une carte de la couverture de terres (2011). II a été observé que $27 \%$ de la zone cultivée 
dans les sept municipalité de BHRJL sont couverts par l'APA, où la production d'épicerie est prédominante, et que les restrictions sur la production agricole de BHRJL ont tendance à provoquer des changements techniques et économiques, qui influencera sur la quantité, la qualité et le prix des produits offerts par les propriété de I'APA par la Grand Goiânia.

Mots-clés: Ribeirão João Leite, Zone de Protection de l'environnement, production d'épicerie, Grand Goiânia.

Introdução

Modificações na cobertura da terra sempre promovem impactos ambientais, sejam eles de natureza e magnitude diretamente locais, ou em uma escala de abrangência regional. É consenso que, à medida que há incremento na intensidade de uso, há aumento de impactos ambientais ou maior potencialidade de ocorrência destes. Tem-se como expressão mais real desta premissa o ambiente urbano das metrópoles, o qual promove grande pressão no meio físico natural, resultado da acelerada expansão da malha urbana e crescimento demográfico (Guerra; Marçal, 2006, p. 28).

Paradoxalmente, à medida que uma cidade cresce, promovendo os mais diversos impactos ambientais, cada vez mais necessita de suporte ambiental no seu entorno, visto que o crescimento demográfico demanda maior uso de recursos naturais. Estes podem variar desde a disponibilidade de materiais para a construção civil até à qualidade dos recursos hídricos para o abastecimento populacional. Nesse contexto, os serviços ambientais promovidos pelos ecossistemas têm grande valor, e interferem diretamente na qualidade de vida da população urbana (Costanza et al., 1997).

Ao aprofundar as questões sobre o ambiente urbano, nota-se que a escala de influência dos processos não se dá apenas em nível municipal, mas em uma abrangência muito maior, principalmente no caso das metrópoles, onde há grande demanda de recursos hídricos e naturais para suprir as necessidades da crescente população. Por outro lado, as necessidades de uma grande cidade não se restringem aos elementos ambientais ou físicos naturais, ou seja, não basta um ambiente conservado e sadio para se resolverem todos os problemas sociais. Há um choque com as demais demandas sociais, como por produtos hortifrutigranjeiros ligados ao abastecimento alimentício, os quais, devido à alta pericidade, muitas vezes são frutos de áreas agrícolas de grande proximidade com os centros consumidores. Portanto, as demandas ambientais de uma grande cidade ultrapassam a questão de conservação dos recursos, como também a escala local. 
Goiânia, assim como Brasília, metrópole planejada no Cerrado, sofreu intensa expansão de sua malha urbana paralelamente à explosão demográfica, o que aumenta a demanda por recursos hídricos, por exemplo. Essas relações de demanda e abastecimento urbano foram materializadas recentemente em Goiânia, com a implantação de um reservatório no Ribeirão João Leite. O reservatório exerce influência sobre o território de sete municípios e sobre uma diversidade de atores com múltiplos interesses.

Com o intuito de assegurar a qualidade da água do reservatório, instituiu-se uma Área de Proteção Ambiental (APA), arbitrando uma série de restrições e imposições para a utilização das terras. Este artigo tem o objetivo de analisar os desdobramentos da influência do reservatório e da criação da APA do Ribeirão João Leite no uso e cobertura da terra, bem como a influência no abastecimento e produção de hortifruti na região.

\section{Área de estudo}

A bacia hidrográfica do Ribeirão João Leite possui área aproximada de 761 km², e abrange os municípios de Goiânia, Anápolis, Nerópolis, Ouro Verde de Goiás, Goianápolis, Campo Limpo e Terezópolis de Goiás (Figura 1). A bacia hidrográfica está inserida no conhecido "Mato Grosso de Goiás”, uma zona de rico potencial agrícola que há décadas é utilizada de forma intensiva para realização de culturas agrícolas e constituição de pastagens (Estevam, 1998, p. 114). A potencialidade da região quanto à agricultura, pecuária e abastecimento já era observada por Faissol (1952), o qual, além de comentar sobre o grande crescimento populacional promovido pela frente pioneira, diz: "esta seria, sem dúvida, a área que abasteceria a futura capital da República, no caso de ela se localizar em Goiás”. Nos dias atuais, a área se configura como a mais importante de Goiás, abrigando os principais núcleos urbanos e grande parte da população, sendo cortada pela Ferrovia Norte-Sul e pela BR 153, principal rodovia do Estado.

A construção do reservatório de abastecimento no Ribeirão João Leite é um esforço conjunto da Agência Nacional de Águas (ANA) e do Saneamento de Goiás S/A (SANEAGO), com prazo estimado para conclusão e início do abastecimento populacional em 2013. O reservatório se integra a um complexo, composto também por uma estação de tratamento 
de água, e abastecerá a Grande Goiânia (Goiânia, Trindade e Aparecida de Goiânia) por aproximadamente 27 anos (SANEAGO, 2012).

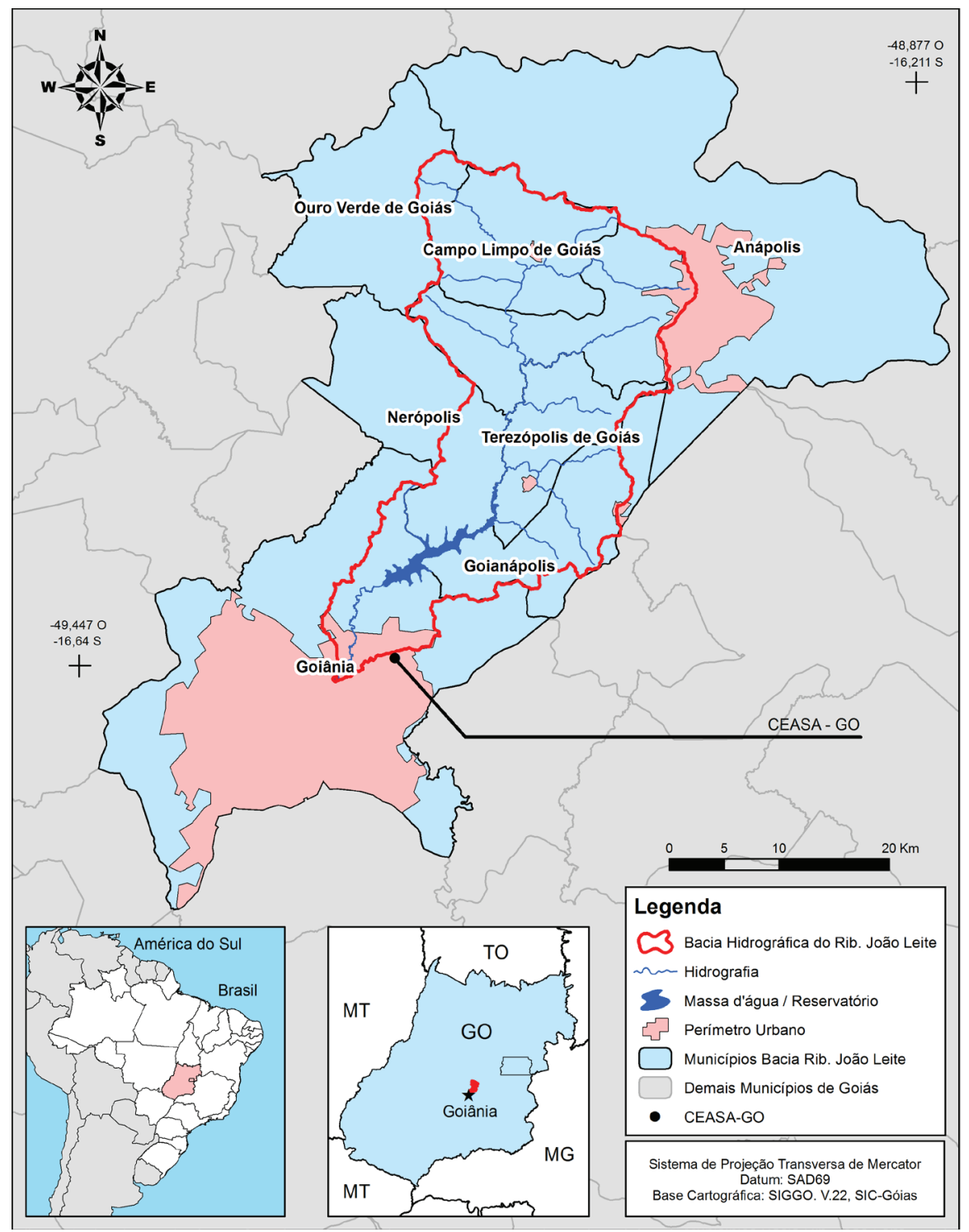

Figura 1 - Localização da Bacia do Ribeirão João Leite, Estado de Goiás - Brasil. 
A motivação para implantação do reservatório foi o aumento da demanda por abastecimento, resultado do expressivo crescimento populacional nos municípios de Goiânia e Aparecida de Goiânia. Em 2010, os dois municípios registraram população total de 1.757.658 habitantes (IBGE, 2012), cerca de 29,3\% da população total do Estado de Goiás (6.003.788 habitantes). Com o reservatório em funcionamento, o principal desafio para a área é conciliar múltiplos interesses e promover a conservação e preservação dos recursos hídricos. Nesse sentido é que o Governo de Goiás, por meio do Decreto Estadual $n^{0}$ 5.704/2002, criou uma unidade de conservação na categoria de Área de Proteção Ambiental (APA). O objetivo é proteger a integridade da bacia de drenagem do Ribeirão João Leite, instituindo normas e restrições para utilização das terras, e, assim, proteger o manancial que servirá água à população.

No decorrer deste trabalho, a discussão transitará entre diferentes escalas de análise e diferentes recortes, uma vez que a Área de Proteção Ambiental do Ribeirão João Leite se limita às terras localizadas na bacia hidrográfica, não contemplando a área integral dos sete municípios de sua área de influência. A APA é composta de fragmentos de cinco municípios e de dois municípios em sua totalidade, enquanto os dados adquiridos na Divisão Técnica Econômica (DITEC) da Central de Abastecimento do Estado de Goiás (CEASA-GO) têm como recorte o município em sua área integral. Logo, é necessário fazer um paralelo entre a área da APA (bacia hidrográfica do Ribeirão João Leite) e toda a extensão territorial dos sete municípios.

\section{Desenho experimental}

O presente estudo foi baseado em análise de três níveis, com objetivo de compreender a produção e abastecimento da população por meio da CEASA-GO. Todos os procedimentos tiveram o intuito de averiguar a especificidade da área de estudo no tocante a áreas cultivadas e oferta de produtos hortifruti. Inicialmente, em nível estadual, fez-se um paralelo entre microrregiões e municípios, depois conferiu-se atenção aos municípios da região de influência do reservatório, os quais possuem território sob o regime da área de preservação ambiental. Para tal análise, foram utilizados dados da Análise Conjuntural 2010, uma publicação da Divisão 
Técnica Econômica (DITEC) da Central de Abastecimento do Estado de Goiás (CEASA-GO).

Para o estudo no nível da bacia hidrográfica do Ribeirão João Leite e sua respectiva área de proteção ambiental, valeu-se de mapeamento de uso e cobertura da terra para o ano de 2011, resultado de classificação digital de uma imagem do satélite Thailand Earth Observation (THEOS), por meio do algoritmo Support Vector Machine (SVM). Inspeção visual e correções vetoriais baseadas em dados de campo foram feitas para melhorar a qualidade do mapeamento. A imagem THEOS proporciona um mapeamento com alto nível de detalhe (1:25.000), a resolução espacial de 2 metros propicia desempenho e acurácia em localizar e identificar alvos.

Por meio da análise do uso e cobertura da terra, foi possível comparar as áreas integrais dos municípios e suas respectivas áreas protegidas e subordinadas às normas da APA. Trabalhos de campo foram realizados para validar o mapeamento de uso e cobertura da terra, por meio de aquisição de pontos de controle e dados da realidade experienciável. A exatidão global (overall accuracy) calculada foi de 90\%. A avaliação das classes do mapa de uso e cobertura por meio dos pontos coletados em campo pode ser conferida no Quadro 1.

Quadro 1 - Avaliação das classes do mapa de uso e cobertura da terra

por meio de dados de campo

\begin{tabular}{|l|c|c|c|c|c|}
\hline \multicolumn{7}{|c|}{ Classes Avaliadas } \\
\hline & Pastagem & Agricultura & Vegetação & Florestamento & Área Úmida \\
\hline Total de pontos coletados & 132 & 68 & 51 & 12 & 5 \\
\hline Validação positiva & 121 & 55 & 47 & 10 & 5 \\
\hline Acurácia por classe & $\mathbf{9 1 , 6 7 \%}$ & $\mathbf{8 0 , 8 8} \%$ & $\mathbf{9 2 , 1 6 \%}$ & $\mathbf{8 3 , 3 3 \%}$ & $\mathbf{1 0 0 , 0 0 \%}$ \\
\hline Overall Acuracy & $\mathbf{8 9 , 6 1 \%}$ & & & \\
\hline
\end{tabular}

Todos os procedimentos metodológicos envolvidos neste estudo são detalhados no fluxograma mostrado na Figura 2. 


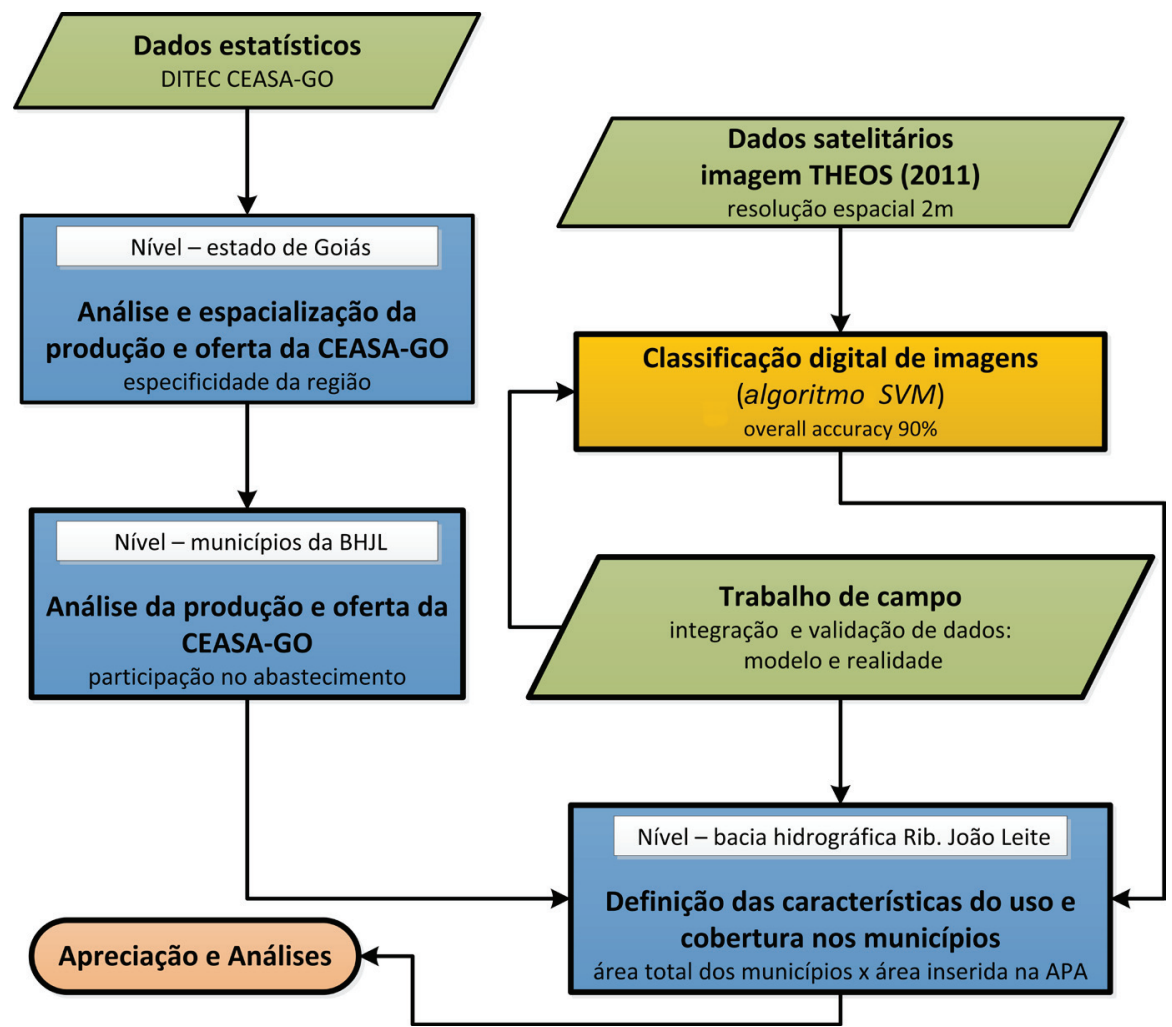

Figura 2 - Fluxograma esquemático referente ao conjunto de dados e procedimentos metodológicos adotados neste estudo

Resultados e discussões

\section{Produção e oferta de hortifruti}

Os dados levantados por meio da Análise Conjuntural (2010) apontam para a especificidade da região quanto ao abastecimento da CEASA-GO (localizada no município de Goiânia). Conforme os dados, as microrregiões de Goiânia e Anápolis somam em torno de 70\% da oferta de produtos, e o restante, aproximadamente $30 \%$, é dividido entre as demais dezesseis microrregiões (Figura 3), com destaque para a região do entorno de Brasília, que concentra 12,07\% da oferta de produtos. 
Tais dados mostram a força do Mato Grosso Goiano quanto à produção e abastecimento da população da Região Metropolitana de Goiânia (RMG). Qualquer intervenção de cunho ambiental e toda política de gestão do território deve considerar tal especificidade, já que a região é fundamental para suprir a demanda de hortifruti da RMG. O reservatório e a bacia do Ribeirão João Leite se encontram inseridos nesse contexto, pois ocupam uma área considerável das microrregiões de maior peso na produção e oferta da CEASA-GO.

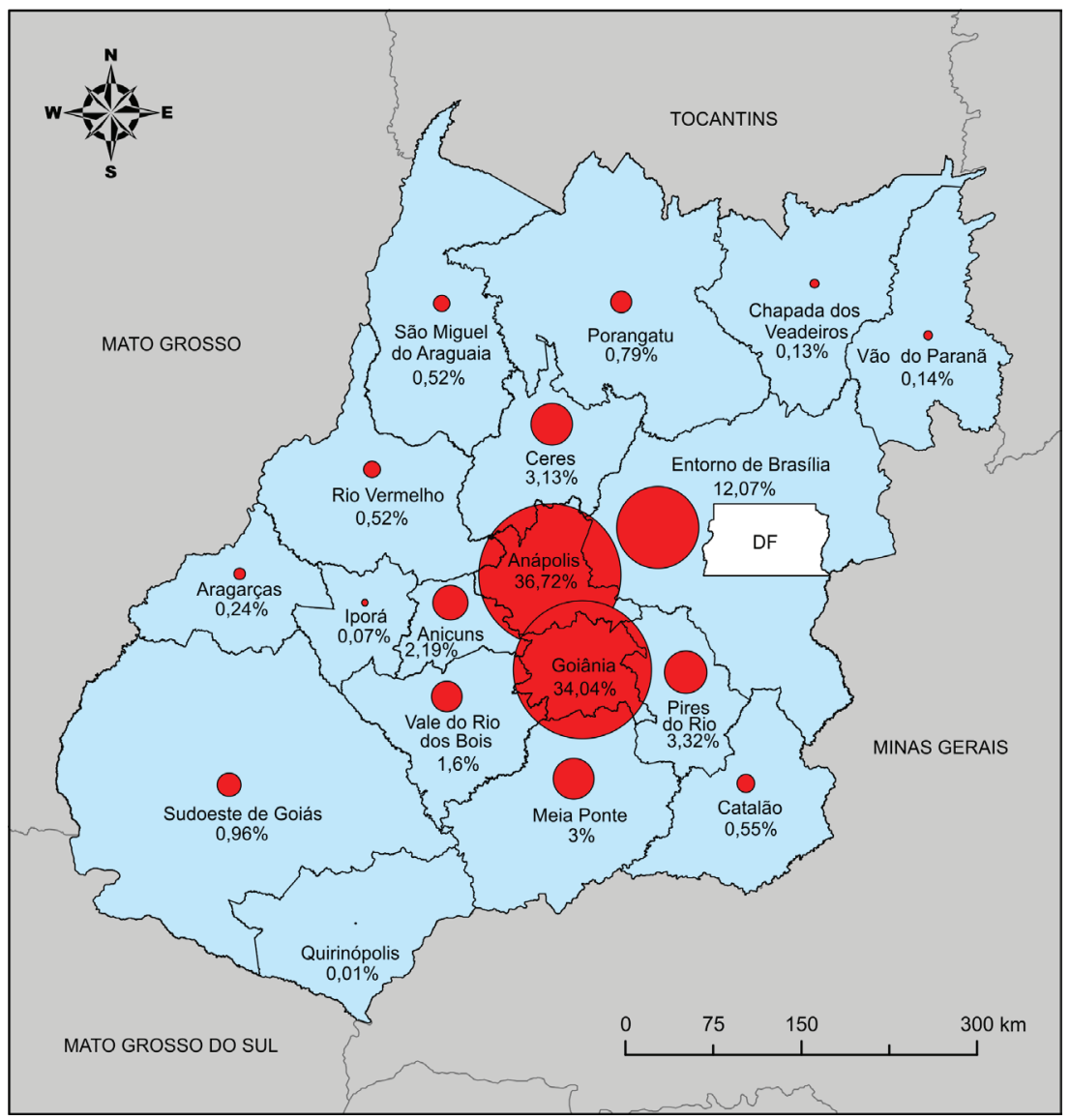

Figura 3 - Mapa das microrregiões do Estado de Goiás e a participação (\%) na oferta da CEASA-GO, 2010

Fonte: DITEC/CEASA (2012) 
Quando se analisa a origem da produção no Estado de Goiás em nível municipal, novamente há um padrão espacial concentrado. Na Figura 4 estão distribuídos os quarenta municípios que mais contribuem no abastecimento da CEASA-GO. Apenas cinco municípios se encontram classificados na faixa de maior contribuição (4,59 até 9,05\%): Goianápolis (9,05\%), Anápolis (8,53\%), Cristalina (7,87\%), Leopoldo de Bulhões $(6,21 \%)$ e Jaraguá $(6,19 \%)$. Considerando que a oferta total proveniente do Estado de Goiás foi de 394.198,45 toneladas, estes cinco municípios

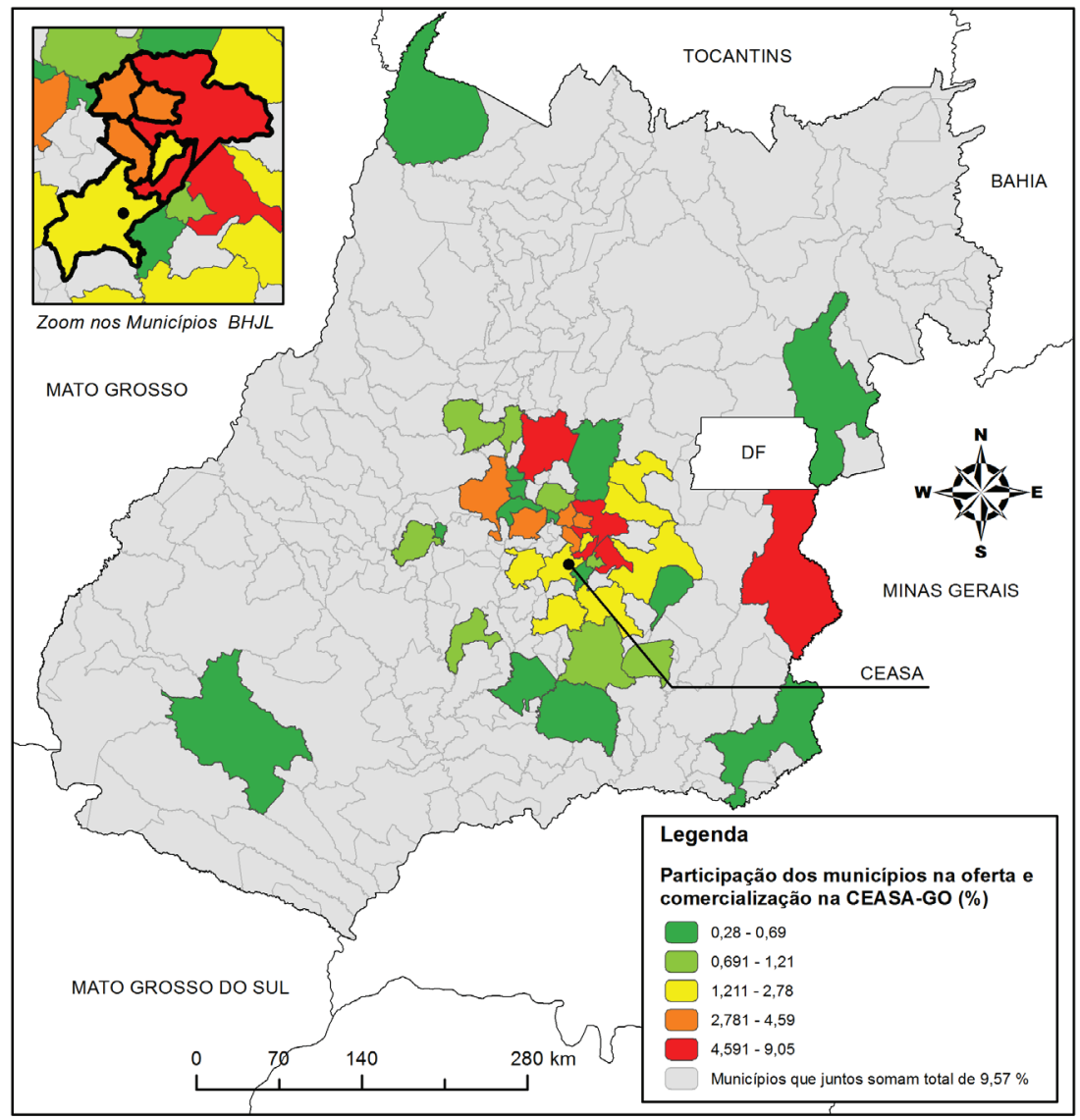

Figura 4 - Mapa de participação dos principais municípios do Estado de Goiás na oferta e comercialização da CEASA-G0, 2010 
sozinhos concentram 37,84\% (em torno de 165.028,38 toneladas). Entre os municípios de maior oferta e que fazem parte da região da APA João Leite, estão os municípios de Anápolis e Goianápolis. Constata-se que o norte do Estado, região mais conservada e de relevo mais acidentado, apresenta pouca oferta de produtos, fato também observado nas regiões sul e sudoeste, as quais apresentam grande extensão de áreas cultivadas, porém com commodities.

É possível notar que alguns municípios não seguem o padrão de concentração dos municípios em torno de Goiânia, como os municípios de Jataí ( $36^{\circ}$ em participação com 0,4 \%), São Miguel do Araguaia $\left(33^{\circ} \mathrm{em}\right.$ participação com 0,5\%), Formosa e Catalão (com 0,28\% e 0,32\% de participação, respectivamente). Em geral, os municípios de maior participação na oferta se encontram próximos a Goiânia, com exceção de Cristalina, no entorno de Brasília, que ocupa o terceiro lugar em participação, com 7,87\% da oferta (34.296,73 ton.).

Na análise dos sete municípios presentes na área do Ribeirão João Leite, nota-se que a área é de grande importância na oferta e comercialização de produtos na CEASA-GO. Estes contribuem em torno de 35\% do total em relação ao Estado e estão entre os principais municípios que mais ofertam produtos. ${ }^{1}$ Na Tabela 1 é possível observar os dados de oferta dos sete municípios.

Tabela 1 - Participação dos municípios na oferta e comercialização da CEASA-G0 em 2010

\begin{tabular}{|l|c|c|c|}
\hline Município & Oferta total (t) & $\begin{array}{c}\text { Participação na oferta } \\
\text { total (\%) }\end{array}$ & Ranking no Estado \\
\hline Goianápolis & $39.449,04$ & 9,05 & 1 \\
\hline Anápolis & $37.185,76$ & 8,53 & 2 \\
\hline Campo Limpo de Goiás & $19.626,29$ & 4,50 & 8 \\
\hline Ouro Verde de Goiás & $19.313,77$ & 4,43 & 9 \\
\hline Nerópolis & $18.226,99$ & 4,18 & 12 \\
\hline Goiânia & $10.317,01$ & 2,37 & 13 \\
\hline Terezópolis de Goiás & $9.193,87$ & 2,11 & - \\
\hline Total & $142.995,72$ & 35,17 & \\
\hline
\end{tabular}

Fonte: DITEC/CEASA (2012) 
Quanto aos principais produtos ofertados na CEASA-GO, a maioria tem parcela produzida nos sete municípios. Estes apresentam participação considerável no volume total disponível para comercialização, sendo fundamentais para suprir a demanda da população da RMG por hortifruti. Entender melhor a procedência de um produto e a quantidade produzida nos municípios de influência da APA pode indicar quais produtos serão afetados pelas restrições impostas pelo plano de manejo. Na Figura 5, é possível conferir a procedência e a porcentagem de participação dos sete municípios sob influência da APA na oferta e comercialização de hortifruti da CEASA-GO.

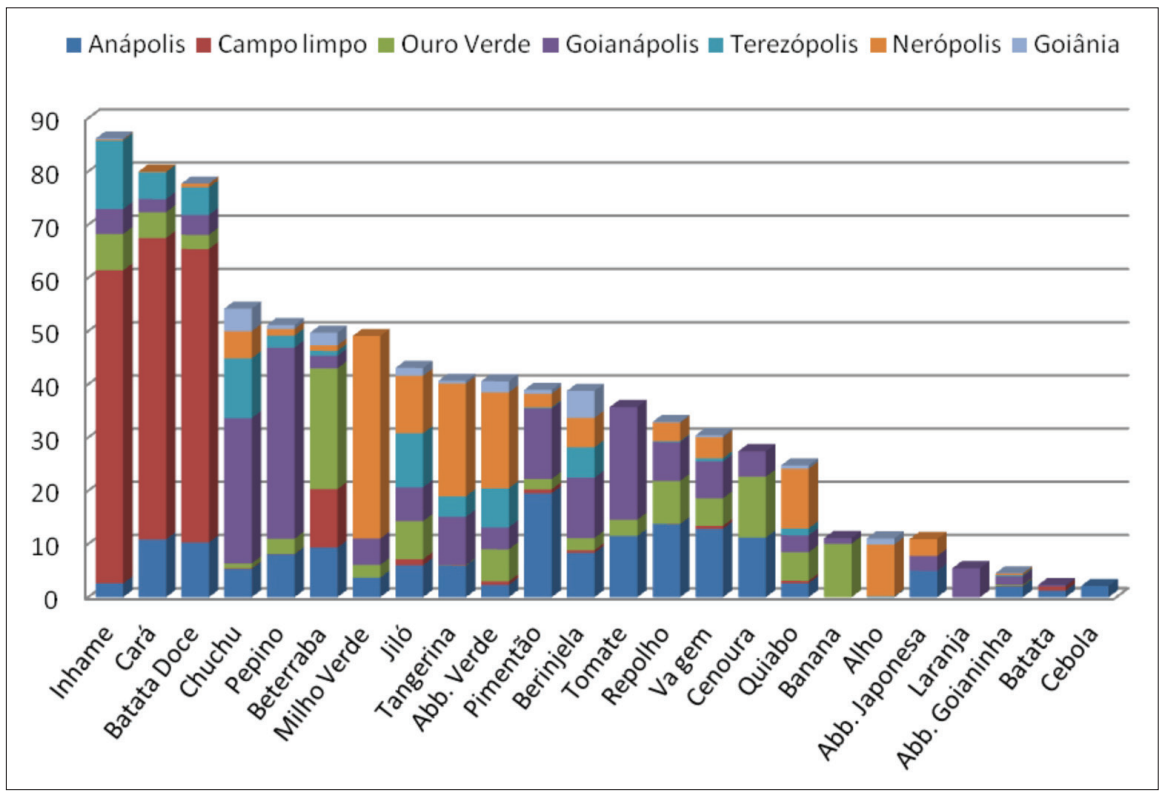

Figura 5 - Procedência dos principais produtos e participação dos sete municípios sob influência da APA do Ribeirão João Leite na oferta e comercialização de hortifrutigranjeiros na CEASA-GO (\%), ano de 2010 Fonte: DITEC/CEASA (2012)

De forma geral, os sete municípios contribuem com mais de 20\% na maioria dos principais produtos ofertados. Campo Limpo, Goianápolis e Nerópolis se destacaram como os municípios de maior participação na oferta e comercialização da CEASA, em 2010. O produto ofertado que 
possui maior dependência dos sete municípios é o inhame: $86,2 \%$ de sua oferta tem origem nos municípios da região do Ribeirão João Leite. Cará (80\%) e batata-doce (77\%) são os produtos que, após o inhame, apresentam maior porcentagem de participação, e procedem majoritariamente do município de Campo Limpo. O município de Goianápolis se destaca na oferta de chuchu, pepino e tomate, com participação de $27,32 \%$, $36 \%$ e $21 \%$, respectivamente. O município de Nerópolis é a principal origem de milho verde: detém 38\% de participação, dos 49\% referentes a quatro municípios,

Produtos como beterraba, jiló, tangerina, abobrinha verde, pimentão, berinjela, repolho, vagem, cenoura e quiabo também têm grande parte de sua oferta dependente dos sete municípios, que apresentaram participação no mínimo acima de $27 \%$ do total em cada um deles. Conclui-se que a participação dos sete municípios não é concentrada em alguns itens, e sim variada, compondo uma série de produtos que provavelmente chegam à mesa dos habitantes da RMG. Isso demonstra a importância desta área para o abastecimento de produtos hortifruti na Grande Goiânia, e a necessidade de inserção desse contexto produtivo no direcionamento de políticas públicas e normas do plano de manejo da APA do Ribeirão João Leite. ${ }^{2}$

\section{Caracterização do uso e cobertura da terra na área de estudo}

Pela análise do mapa de uso e cobertura da terra para toda a extensão territorial dos sete municípios (Figura 6), constata-se que a cobertura predominante é de pastagens, que somam 46,3\% da área total $\left(1.155 \mathrm{~km}^{2}\right)$, distribuídas pelos sete municípios. Estas também predominam na bacia hidrográfica do Ribeirão João Leite, ocupando 59,40\% de sua área. Portanto, de forma comparativa, a bacia hidrográfica possui maior concentração de pastagens.

Cabe ressaltar que a intensa cobertura por pastagens não garante um grande efetivo bovino (Tabela 2). Muitas das vezes, essas áreas de pastagens (mais próximas de Goiânia) estão ociosas ou com baixa lotação devido à especulação imobiliária direcionada para a região, dinamizada pela descentralização da capital goiana. As pastagens também são predominantes na área de preservação às margens do reservatório de abastecimento. Desprovidas de cobertura vegetal, essas áreas estão sujeitas a processos erosivos e podem comprometer a qualidade da água. 


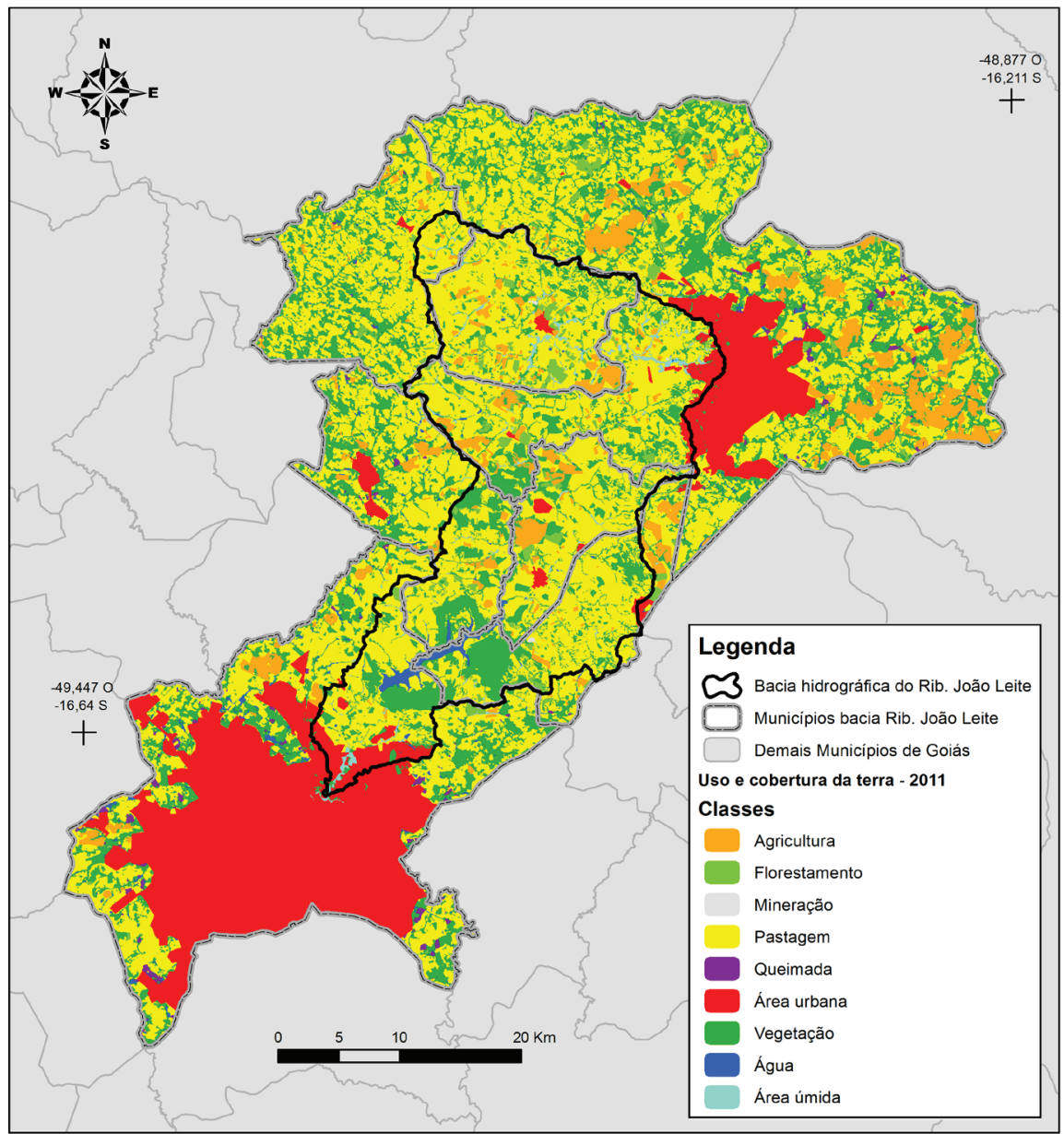

Figura 6 - Mapa de uso e cobertura da terra para os municípios com área presente na bacia do Ribeirão João Leite (2011) Imagem base do satélite Thailand Earth Observation (THEOS), Overall Accuracy de 90\%

Quanto às áreas destinadas à produção de cultivares, é nítida sua concentração na região leste do município de Anápolis, que possuía em 2011 uma área cultivada de $91,71 \mathrm{~km}^{2}$, dos quais apenas 12,04 km² (13\%) estão localizados na bacia hidrográfica do Ribeirão João Leite. Também são observadas áreas cultivadas expressivas nos municípios de Goianápolis, Terezópolis e Campo Limpo de Goiás. Os municípios com maior percen- 
tual de áreas cultivadas na bacia hidrográfica são os municípios de Campo Limpo de Goiás, com 99,8\% (14,54km²), e Terezópolis de Goiás, com 100\% $\left(9,86 \mathrm{~km}^{2}\right)$. Os territórios destes municípios estão de forma integral na área de preservação, o que exige a adequação de praticamente todos os produtores rurais ao plano de manejo da APA do Ribeirão João Leite.

Tabela 2 - Efetivo bovino e cabeça por hectare (2011)

\begin{tabular}{|l|c|c|c|}
\hline Município & $\begin{array}{c}\text { Efetivo bovino } \\
\text { (cab.) }\end{array}$ & $\begin{array}{c}\text { Área de } \\
\text { pastagem }^{\mathbf{1}} \text { (ha) }\end{array}$ & $\begin{array}{c}\text { Lotação } \\
\text { cab./ha }\end{array}$ \\
\hline Anápolis & 72.000 & 42770 & 1,68 \\
\hline Campo Limpo de Goiás & 15.000 & 10383 & 1,44 \\
\hline Goianápolis & 13.000 & 9422 & 1,38 \\
\hline Goiânia & 35.600 & 21554 & 1,65 \\
\hline Nerópolis & 40.000 & 11174 & 3,58 \\
\hline Ouro Verde de Goiás & 30.000 & 13552 & 2,21 \\
\hline Terezópolis de Goiás & 15.000 & 6656 & 2,25 \\
\hline
\end{tabular}

Fonte: IBGE. 'Área de pastagem oriunda do mapa de uso e cobertura da terra

De forma geral, apenas $27 \%$ das áreas cultivadas em toda a extensão dos sete municípios se encontram dentro dos limites da APA (Tabela 4). A quantidade parece insignificante, entretanto a área da bacia hidrográfica do Ribeirão João Leite tem uma extensão de apenas 30\% $\left(761,6 \mathrm{~km}^{2}\right) \mathrm{em}$ relação a toda a área dos municípios envolvidos (em torno de $2493 \mathrm{~km}^{2}$ ). Na Tabela 3, é representada a extensão das áreas cultivadas em cada município, a área cultivada que se encontra no limite da APA, e a porcentagem da área cultivada localizada dentro da APA, em relação ao total do município.

Tabela 3 - Extensão total da área com cultivo agrícola em cada município e proporção abrangida pela APA do Ribeirão João Leite.

\begin{tabular}{|l|c|c|c|}
\hline \multirow{2}{*}{ Município } & \multirow{2}{*}{$\begin{array}{c}\text { Área cultivada total } \\
\left(\mathbf{K m}^{\mathbf{2}} \mathbf{)}\right.\end{array}$} & \multicolumn{2}{|c|}{ Extensão cultivada na APA } \\
\cline { 3 - 4 } & 91,71 & 12,04 & Aercentual do total \\
\hline Anápolis & 14,56 & 14,54 & 13,1 \\
\hline Campo Limpo de Goiás & 9,91 & 1,48 & 99,9 \\
\hline Goianápolis & 14,18 & 0,49 & 15,0 \\
\hline Goiânia & 10,41 & 3,12 & 3,5 \\
\hline Nerópolis & 4,80 & 0,76 & 30,0 \\
\hline Ouro Verde de Goiás & 9,86 & 9,86 & 15,9 \\
\hline Terezópolis de Goiás & & & 100,0 \\
\hline
\end{tabular}


O município de Anápolis, mesmo possuindo apenas 13\% (12 km²) de sua área cultivada em área de preservação, ocupa o segundo lugar no que diz respeito à quantidade de áreas cultivadas em locais com restrições, superando o município de Terezópolis, por exemplo, que possui $100 \%\left(9,86 \mathrm{~km}^{2}\right)$ de sua área protegida pela APA. Tais dados demonstram a importância do município de Anápolis na produção de cultivares. Em termos hierárquicos quantitativos, os municípios com maiores áreas cultivadas em áreas protegidas pela APA são: Campo Limpo de Goiás (14,56 $\left.\mathrm{km}^{2}\right)$, Anápolis $\left(12,04 \mathrm{~km}^{2}\right)$ e Nerópolis $(10,41$ km²).

As áreas urbanizadas - concentradas em Goiânia $(362,4$ km²) e Anápolis $\left(102,2 \mathrm{~km}^{2}\right)$ - constituem o tipo de cobertura de maior discrepância quanto à extensão, entre os municípios. Esses dois municípios somam 97\% de toda a cobertura urbana, realidade muito diferente de municípios como Ouro Verde de Goiás, que possui área com cobertura e uso urbano de aproximadamente $0,65 \mathrm{~km}^{2}$, apenas $0,13 \%$ do total de toda a área urbanizada. Em termos quantitativos, o município de Nerópolis possui a terceira maior área urbana, com $3,37 \mathrm{~km}^{2}$, valor bastante reduzido em relação a Anápolis, que ocupa a segunda posição.

As classes de cobertura "florestamento", "mineração" e "área úmida” estão distribuídas de forma fragmentada pelos municípios, com destaque para Anápolis, que concentra uma área de 27,19 km², $51 \%$ da área total florestada. Tal fato pode estar relacionado com a utilização de madeira nas olarias, presença numerosa no extenso território anapolino, bem como em Campo Limpo de Goiás. As áreas com corpos hídricos, além de pequenos represamentos, se resumem principalmente ao maior corpo que é o reservatório, com área aproximada de 12,2 km² e que abrange territórios de Goiânia, Goinápolis, Nerópolis e Terezópolis de Goiás.

Na Tabela 4, é possível conferir o paralelo da distribuição das classes de cobertura e uso da terra, entre a extensão territorial dos sete municípios e a área de preservação ambiental, bem como acompanhar as proporções calculadas.

Para Raffestin (1993, p. 143), "o território se forma a partir do espaço, é o resultado de uma ação conduzida por um ator sintagmático em qualquer nível”. Cavalcanti (1998, p.107) nos informa que nas análises científicas atuais, um dos elementos que têm sido apontados com destaque na constituição do conceito de território é o poder, afirmativa reforçada por Andrade (1995, p. 19): “o território está associado à ideia de poder, de 
controle”. Pensamos que as ações de controle podem ser desempenhadas pelo Estado, na medida em que ele ocupa a posição de sustentáculo da ordem, regulador e implementador de políticas públicas, por meio de uma série de medidas, como legislação e regulamentos (Coelho, 2005). Não obstante, podemos trazer novamente a contribuição de Raffestin, segundo a qual o Estado, como único núcleo de poder, limita a capacidade da análise geográfica, "o que não é aceitável na medida em que existem múltiplos poderes que se manifestam nas estratégias regionais ou locais" (Raffestin, 1993, p. 17).

Tabela 4 - Extensão das classes de cobertura e uso da terra nos sete municípios e na Área de Proteção Ambiental do Ribeirão João Leite

\begin{tabular}{|c|c|c|c|c|}
\hline \multirow{2}{*}{ Classe } & \multicolumn{2}{|c|}{$\begin{array}{c}\text { Extensão da cobertura ou } \\
\text { uso na bacia }\end{array}$} & \multicolumn{2}{|c|}{ Extensão da cobertura ou uso nos municípios } \\
\hline & Área $\left(\mathbf{k m}^{2}\right)$ & Percentual & Área total $\left(\mathrm{km}^{2}\right)$ & $\begin{array}{l}\text { Percentual do total } \\
\text { inserido na bacia }\end{array}$ \\
\hline Vegetação & 178,60 & 23,45 & 588,79 & 30,33 \\
\hline Área úmida & 15,75 & 2,07 & 17,00 & 92,65 \\
\hline Água & 14,25 & 1,87 & 31,52 & 45,21 \\
\hline Florestamento & 23,06 & 3,03 & 52,90 & 43,60 \\
\hline Pastagem & 452,43 & 59,40 & $1.155,11$ & 39,17 \\
\hline Agricultura & 42,31 & 5,55 & 155,43 & 27,22 \\
\hline Área urbana & 34,90 & 4,58 & 479,07 & 7,29 \\
\hline Mineração & 0,38 & 0,05 & 0,38 & 100,00 \\
\hline Queimada & 0,00 & 0,00 & 13,51 & 0,00 \\
\hline Total & 761,69 & 100,00 & $2.493,71$ & - \\
\hline
\end{tabular}

Conflitos e atores no uso e cobertura da terra

Nesse sentindo, podemos refletir sobre a APA do Ribeirão João Leite como um território delimitado por um decreto estadual, que não tem suas condições internas satisfeitas de forma natural, isto é, não foram as relações de poder endógenas que delimitaram o território, mas, sim, a ação de um agente exógeno (Estado), verticalizada e hegemônica. Tais características, certamente, fazem da APA, com seus múltiplos atores, um grande campo de choque de estratégias e interesses. Aqui, especificamente, interessa refletir sobre os conflitos entre os atores, no que diz respeito ao uso e cobertura da terra e à possível influência da implementação das normas 
estabelecidas no plano de manejo da APA do Ribeirão João Leite, na produção e oferta de hortifruti.

O primeiro ponto a ser destacado quanto à atuação no território da APA do João Leite é a desarticulação entre os gestores municipais. Tal fato se dá, principalmente, porque os benefícios da implantação do reservatório e consequente criação da APA se concentram totalmente no município de Goiânia. Para os demais municípios, sobraram restrições e limitações para a utilização das terras, o que ocasiona divergência de interesses. Para Goiânia, quanto menos intensidade de uso ocorrer na bacia, maior será a qualidade da água fornecida, e menor serão os custos da SANEAGO com tratamento hídrico e manutenção do equilíbrio ambiental da área de preservação do reservatório. Já municípios como Terezópolis de Goiás, por exemplo, manifestam-se de forma contrária às limitações e imposições de uso, alegando prejudicar oportunidades de investimentos externos na região. "Terezópolis não pode parar por causa de Goiânia” (divulgação prefeitura municipal de Terezópolis, 2012). Para Terezópolis de Goiás, as limitações e imposições estão ligadas à grande especulação imobiliária resultante de empreendimentos do tipo condomínio fechado, a maioria com discurso de benefício público, mas que na verdade não são direcionados para a população local.

Tal iniciativa por parte de Terezópolis pode ser considerada irresponsável, já que a cidade também é abastecida por mananciais de afluentes do Ribeirão João Leite, situação similar a de Campo Limpo de Goiás. Considerando que estes municípios estão totalmente dentro da bacia de drenagem, a dependência dos recursos hídricos existentes na bacia é tão grande quanto a de Goiânia.

Em situação delicada estão os agricultores, principalmente os de produção familiar, donos de pequenas propriedades e que vivem da renda da terra. O plano de manejo que normatiza o uso da terra na APA institui proibição de utilização de agrotóxicos das classes I, II e III, permitindo o uso de classe toxicológica IV (pouco ou muito pouco tóxica), além de limitar a utilização de áreas para agricultura, represamento e captação de água. Os agrotóxicos da classe IV apresentam menor potencial de periculosidade ambiental, porém possuem menor poder de conter pragas, podendo promover o aumento do custo da produção ou até inviabilizar o cultivo de algumas espécies.

Por enquanto, pouca intervenção no que diz respeito à fiscalização e coibição de utilização de agrotóxicos tem sido feita. Relatos de pro- 
dutores rurais, obtidos em campo, demonstram que as atividades estão sendo desenvolvidas normalmente, porém eles estão temerosos quanto às intervenções que serão efetuadas na área, principalmente quanto à sua continuidade de produção. Os produtores reclamam da carência de informações sobre o plano de manejo, suas restrições e as propostas alternativas para a área. Outros alegam que encontram dificuldades em proteger suas áreas de preservação permanente (APP), solicitando a contrapartida de um poder público muito pouco presente em benefícios, mas bastante presente em autuações.

Uma iniciativa para apoiar os produtores rurais da área é a possível implementação do programa "Produtor de Água", da Agência Nacional de Águas (ANA), em que aqueles que aderirem receberão incentivos financeiros, técnicos e materiais para preservar e recompor sua área, bem como uma espécie de Royalties mensais sobre o valor da água comercializada pela SANEAGO. Esse tipo de pagamento por serviço ambiental (PSA) foi implementado com sucesso em outros lugares do Brasil, como em Extrema, no Estado de Minas Gerais, município produtor de quantidade considerável da água consumida na Grande São Paulo. No próprio Estado de Goiás se tem registro do programa. Produtores rurais do município de Rio Verde recebem até $\mathrm{R} \$ 124,17$ mensais por uma nascente preservada (lei municipal de Rio Verde, $\mathrm{n}^{0}$ 6.033/2011). O PSA é um incentivo que considera a propriedade rural uma unidade produtora de água, responsável por abastecer o meio urbano.

É importante o estabelecimento de alianças bem sucedidas com os produtores rurais, visto que esta unidade, a propriedade rural, é a de maior importância na gestão ambiental da área e na garantia da qualidade da água do reservatório. Análises efetuadas pela SANEGO (2005) apontaram para um padrão de qualidade da água classe II e III, com alto teor de fosfato (fertilizante), e em época chuvosa foi registrada elevada turbidez da água nos cursos. Nesse sentido, destaca-se a importância de atividades que promovam o uso racional de fertilizantes e controlem o revolvimento do solo, impedindo o transporte de partículas para o reservatório.

\section{Considerações finais}

Os dados levantados demonstram a expressiva contribuição de produtores rurais dos municípios de influência da APA na oferta e co- 
mercialização de gêneros hortifruti na CEASA-GO. Tal contribuição se dá em quantidade e em variedade, sendo os principais produtos ofertados: inhame, cará, batata-doce, chuchu, pepino, beterraba, milho verde, jiló, tangerina, abobrinha verde, pimentão, berinjela, tomate, repolho, vagem, cenoura, quiabo. Os produtos que podem sofrer impacto em sua produção são aqueles que têm como procedência principal os municípios de Campo Limpo de Goiás e Terezópolis de Goiás, pois estes possuem seus limites totalmente inseridos na APA. Os dois municípios produzem 71\% do inhame, $61 \%$ do cará e $60 \%$ da batata-doce. Portanto, em análise preliminar, estes são os produtos que podem sofrer maior alteração caso seja limitada a produção.

Além disso, a oferta de outros dez produtos depende da produção desenvolvida nos municípios da BHRJL, o que indica que as restrições à produção agropecuária tendem a provocar mudanças técnicas e econômicas que irão influenciar na quantidade, qualidade e preço dos produtos ofertados pelas propriedades rurais da APA à Grande Goiânia.

Para os municípios que possuem extensão total sob regime da APA, deve ser direcionado um olhar especial, principalmente no que diz respeito ao desenvolvimento de programas ambientais e sociais, a fim de se evitarem problemas após a conclusão do Sistema João Leite e início das fiscalizações quanto às recomendações de plantio e utilização de agrotóxicos.

O mapa de uso e cobertura da terra demonstrou que a predominância na área é de pastagens, e que apenas $27 \%\left(155,4 \mathrm{~km}^{2}\right)$ das áreas de agricultura dos sete municípios se encontram em área de preservação. As maiores áreas de cultivo de Goianápolis e Anápolis se encontram fora dos limites da APA, porém as áreas agrícolas dentro da APA são, predominantemente, dedicadas ao cultivo de hortifruti, e certamente são importantes no abastecimento da população da Grande Goiânia. Nesse sentido, é crucial estabelecer uma conexão entre a preservação e a utilização, pois a produção de hortifruti desta área não pode ser afetada pelas limitações de uso impostas pela APA. Alternativas e oportunidades devem ser oferecidas aos agricultores, como implementação de orientações técnicas e, principalmente, a implantação, com sucesso, do programa "Produtor de Água”.

A necessidade de uma gestão integrada para a área é eminente. No entanto, os interesses múltiplos dificultam a gestão ideal para este território, uma gestão que, perpassada pelos olhares de agentes de interesses 
muito distintos, se torna um verdadeiro desafio. A visão atual é: o que traz benefício para um agente traz necessariamente prejuízo a outro. Desfazer essa realidade é primordial para um início de conciliação entre atividades de preservação e meio econômico. A SANEAGO e a ANA devem realizar atividades nesse sentido, sensibilizando os demais agentes e satisfazendo seus anseios e necessidades, com destaque, principalmente, para o pequeno produtor rural. Cabe ao Ministério Público do Estado de Goiás o papel importante de mediar esses conflitos e colaborar para a promoção de uma gestão integrada e participativa, no sentido de promover um bem maior para todos.

\section{Agradecimentos}

Este trabalho se insere entre as várias iniciativas do Laboratório de Processamento de Imagens e Geoprocessamento do Instituto de Estudos Socioambientais da Universidade Federal de Goiás (LAPIG/IESA/UFG - www.lapig.iesa. ufg.br), voltadas ao monitoramento sistemático e gestão territorial em áreas de Cerrado. O autor agradece ao Conselho Nacional de Desenvolvimento Científico e Tecnológico (CNPq) e à OSCIP Bioma Brasil pelo incentivo e contribuição na realização deste estudo.

\section{Notas}

1. Esse padrão de espacialização da produção de hortifruti, além de ter ligação com a forma como o território goiano foi ocupado (expansão de fronteira agrícola sul/sudeste, principais rodovias, antiga estrada de ferro), e com as condições naturais (principalmente fertilidade do solo/relevo), também sofre influência da logística de transporte; como os produtos são perecíveis, a distância de transporte se configura um fator importante, além de que é comum a figura do "atravessador", um intermediário que se encarrega de adquirir os produtos nas "porteiras das propriedades" levando-os para negociar na CEASA-GO.

2. Os dados ora apresentados são registros da CEASA-GO. Cabe ressaltar que na Grande Goiânia existem feiras livres e supermercados nos quais os produtos provenientes da bacia do Ribeirão João Leite são comercializados sem, necessariamente, terem passado pela CEASA-GO. Também é importante pontuar que a produção é conjuntural, ou seja, ao longo do tempo pode-se mudar tanto o produto cultivado como a quantidade deste, e, em casos não raros, os produtores podem produzir hortifruti ou não, dependendo de sua situação econômico-familiar. 


\section{Referências}

ANDRADE, M. C. A questão do território no Brasil. São Paulo: Hucitec; Recife: IPESPE, 1995.

CAVALCANTI, L. S. Geografia, escola e construção de conhecimentos. Campinas: Papirus, 1998.

CEASA-GO - Central de Abastecimento do Estado de Goiás. Divisão Técnica e Econômica. Análise Conjuntural 2010 nº 35. Goiânia, 2011.

COELHO, M. C. N. Impactos ambientais em áreas urbanas - teorias, conceitos e métodos de pesquisa. In: GUERRA, A. J. T.; CUNHA, S. B. da (Orgs.). Impactos ambientais urbanos no Brasil. 3. ed. Rio de Janeiro: Bertrand Brasil, 2005. 416 p.

CONSTANZA, R,; D’ARGE, R.; GROOT, R.; FARBERK, S.; GRASSO, M.; HANNON, B.; LIMBURG, K.; NAEEM, S.; PARUELO, J.; RASKIN, R. G.; SUTTON, P. \& VAN DEN BELT, M. The value of the world's ecosystem services and natural capital. Nature, v. 387, p. 253-260, 1997.

ESTEVAM, L. O tempo da transformação: estrutura e dinâmica da formação econômica de Goiás. Goiânia: Ed. do Autor, 1998.

FAISSOL, S. O Mato Grosso de Goiás. Rio de Janeiro: Instituto Brasileiro de Geografia e Estatística; Conselho Nacional de Geografia, 1952.

GUERRA, A. J. T.; MARÇAL, M. dos S. Geomorfologia Ambiental. Rio de Janeiro: Bertrand Brasil, 2006. 192p.

INSTITUTO BRASILEIRO DE GEOGRAFIA E ESTATÍSTICA (IBGE). Censo demográfico 2010: resultados. Disponível em: <http://www.ibge.gov.br/home/ estatistica/populacao/censo2010/>. Acesso em: 3 ago. 2012.

PREFEITURA MUNICIPAL DE TEREZÓPOLIS DE GOIÁS, 2012. Prefeito defende no MP estadual os empreendimentos em Terezópolis. Disponível em: <http:// terezopolisdegoias.webnode.com.br/news/prefeito-defende-no-mp-estadual-osempreendimentos-em-terezopolis/>. Acesso em: 22 jun. 2012.

RAFFESTIN, C. Por uma geografia do poder. Tradução de Maria Cecília França. São Paulo: Ática, 1993.

SANEAGO, 2005. UFG. Projeto C6 - Estudos de capacidade de assimilação de resíduos tóxicos e de carga orgânica pelo reservatório. Goiânia: Escola de Agronomia e de Engenharia de Alimentos, UFG, 2005.

SANEAGO, 2012. As obras do Sistema que vai abastecer moradores da Grande Goiânia até o ano de 2040 serão visitadas pelo governador Marconi Perillo nesta sexta-feira. Disponível em: <http://www.saneago.com.br/>. Acesso em: 3 ago. 2012.

SECRETARIA DO MEIO AMBIENTE E DOS RECURSOS HÍDRICOS (SEMARH). Instituto de Desenvolvimento Tecnológico do Centro-Oeste (ITCO). Plano de Manejo APA João Leite. Goiânia, 2007. 
Silvio Braz de Sousa - Técnico em Mineração pelo Centro Federal de Educação Tecnológica de Goiás/CEFET Graduado em Geografia pela Universidade Federal de Goiás - Mestrando em Geografia na mesma universidade.

Recebido para publicação em 27 de abril de 2013 Aceito para publicação em 3 de julho de 2013 